\title{
Diálogos entre arte e ilustração: uma coleção infantil para Portinari
}

\author{
Julia Lima L. Carvalho \\ PUC-Rio
}

\begin{abstract}
Resumo
A experiência na criação de uma série de livros infantis sobre o pintor Cândido Portinari levantou algumas questões, e muitas decisões de projeto surgiram da tensão entre a arte, o design e a ilustração. A imagem como narrativa, o papel do design nessa construção e sua relação com a arte, e finalmente, a relação com o leitor, são algumas das preocupações que surgiram no processo.
\end{abstract}

Palavras-chave: ilustração, arte, livro infantil

\begin{abstract}
This paper describes the experience of making a children's book series about the painter Cândido Portinari. The experience raised some questions, and many of the project's decisions emerged from the tension between art, design and illustration. The image as a narrative, the role of design and its relation with art, and finally the relation with the reader were some of the concerns that came up in the process.
\end{abstract}

Keywords: illustration, art, children's book

\section{INTRODUÇÃO}

Partindo de um projeto de coleção de livros paradidáticos, e os problemas encontrados no processo, o artigo aborda a relação da ilustração com as obras de arte e, principalmente, sua relação com o leitor. A maior questão levantada ao longo do projeto era como estaríamos moderando a apresentação da obra de Cândido Portinari para o público infantil através de um projeto de design e ilustração. Buscado a melhor compreensão do papel do designer como mediador nessa relação específica olhamos não apenas para a própria experiência de projeto como para outros exemplos onde essa relação é coloca em pauta.

Em um primeiro momento é preciso situar a ilustração em relação à arte e ao design, e como a discussão dessas definições em si já adianta algumas das questões levantadas na fase de projeto. Em seguida devemos considerar a especificidade da ilustração editorial e, nesse sentido também, as diferentes formas de atuação do designer nesse campo observando as possibilidades de mediação e a relação texto e imagem. Assim teremos um panorama para basear a reflexão acerca do processo de 
criação dos livros aqui analisados, e os problemas levantados ao longo, para finalmente apontar a perspectiva da ilustração enquanto projeto e solução de design dentro desse contexto.

Dentro do campo didático e pedagógico que já faz parte das ações do Projeto Portinari, produzimos uma coleção de treze volumes (entre livros do aluno e do professor) com propostas de atividade a serem trabalhadas em sala de aula. Os volumes são divididos pelas temáticas tratadas por Portinari, contextualizando as obras dentro de uma narrativa própria. Apesar de serem uma coleção, cada livro pode funcionar separadamente, seriam eles: "Os Meninos", "As Meninas", “As Brincadeiras", "Festas Brasileiras", "Festa na Floresta", "Riquezas do Brasil" e "História do Brasil em Traços e Cores".

Fazer um livro infantil sobre a obra de Cândido Portinari gerou uma série de questões muito além do projeto de design em si. Apesar de muitas imagens desse artista terem uma temática próxima ao universo infantil, a ideia de um livro com uma sequência de suas pinturas não parecia interessante para aquele público. O livro de arte muitas vezes traz um aspecto inacessível e pouco convidativo para uma criança.

A grande questão era então como atrair o público infantil para a obra do pintor, deixando-a em primeiro plano e ao mesmo tempo trazendo o leitor para dentro de uma narrativa. Usar artifícios da ilustração e trazer elementos ou linguagens familiares do universo infantil eram algumas das possibilidades levantadas.

No início do processo se revelou surpreendente que muitos dos livros de arte para criança usem como recurso ilustrações que fazem uma espécie de mediação entre a obra e o leitor, em um sentido aparentemente de deixá-la mais palatável. Muitos não trazem sequer na capa uma imagem original do artista como nos exemplos abaixo.
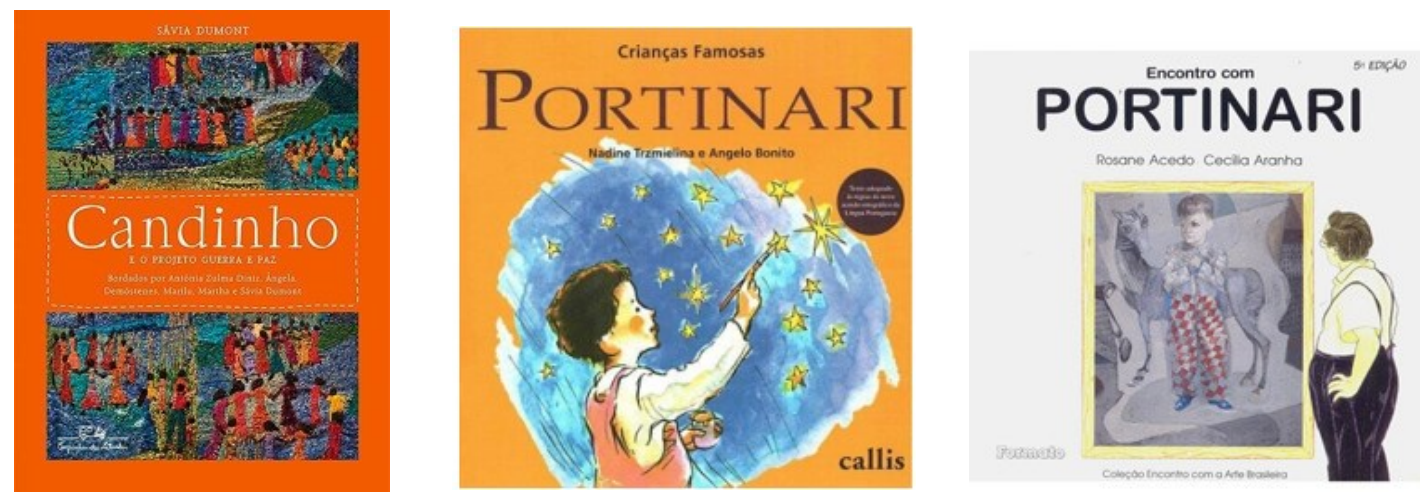
[Fig.1 “Candinho", Savia Dumont | Fig.2. "Crianças Famosa- Portinari, Nadine Trzmielina | Fig. 3 "Encontro com Portinari", Rosane Acedo e Cecilia Aranha]

Inclusive no site do Projeto Portinari, antes de uma atualização de layout, a imagem que chamava para a área destinada às crianças trazia uma ilustração que não foi feita pelo pintor para, aparentemente, se aproximar do público infantil. Independente de pensar sobre a qualidade das ilustrações, é curioso que, nesse caso, onde a apresentação da obra do artista é o principal propósito, elas sejam tão necessárias e numerosas.

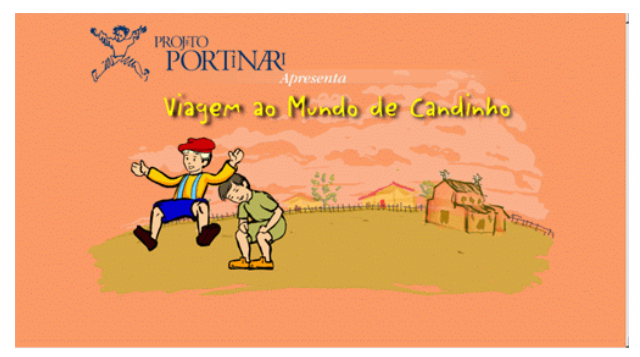

[Fig. 4, imagem retirada do site do Projeto Portinari em 2012]

Uma hipótese é que seria uma maneira bastante objetiva de separá-la de um conteúdo 'adulto'. Se trataria, portanto, de outra linguagem, ou seja, uma forma de se comunicar com o leitor que independe do texto escrito para levar aquele conteúdo, no caso a obra de um artista, e dar um sentido que uma sequência de obras isoladas não teriam. Além disso, uma criança conseguiria identificar de forma clara que aquele conteúdo fora projetado para ela.

Certamente uma das maneiras mais interessantes de se apresentar um conteúdo novo é contando uma história. Uma referência conhecida de livro de arte para criança é "Linéia nos Jardins de Monet"; nele uma menina conhece a obra e a vida de Monet e fala de suas impressões enquanto passeia em seu famoso jardim de Giverny. As pinturas se integram na narrativa como quadros dentro das ilustrações que narram o percurso da personagem. As ilustrações de Linéia situam a personagem em um mundo paralelo às obras de Monet, e podemos visitar o jardim que serviu de inspiração para o pintor através das ilustrações de Lena Anderson, fotografias e claro, das pinturas do próprio artista. 

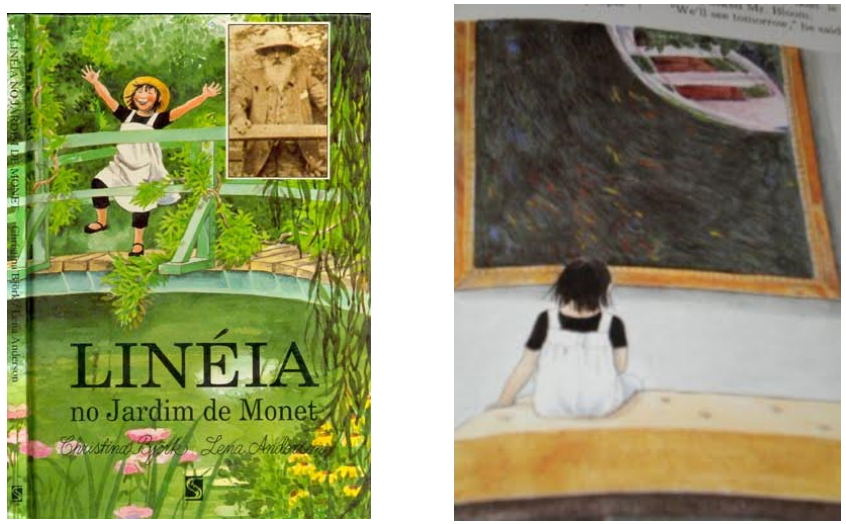

[Fig.5, "Linéia no Jardim de Monet", Christina Bjork]

Outro recurso bastante frequente de aproximação com a criança é lembrar do próprio artista na infância e traçar paralelos com sua obra. Dessa maneira as obras não estão integradas nas ilustrações que retratam sua vida, mas claramente separadas e referenciadas de forma diferente da perspectiva de "Linéia", por exemplo.

Em todos os casos, a arte e a ilustração fazem parte de um mesmo projeto de design. A arte aqui é uma obra que deve ser apresentada à nova geração e, dessa forma, está suficientemente legitimada dentro de um sistema de arte e colocada dentro de um contexto histórico determinado. Seu valor está não só nela mesma enquanto imagem, mas em tudo que ela representa historicamente. Já a ilustração é o que está apresentando a história daquele artista em imagens diretamente relacionada ao texto verbal. As imagens do artista e do ilustrador são claramente distintas e não se confundem. O papel do designer nessa mediação pode se tornar fundamental, e nesse ponto encontramos interessantes pontos de interseção entre arte, ilustração e design.

\section{ILUSTRAÇÃO ENTRE ARTE E DESIGN}

Comparados a outros meios de representação da cultura como a arte, o cinema etc., o design está corporificado na realidade palpável. Ele nos indica dentro do mundo a forma de nos portar, os limites de convivência, o lugar social dos indivíduos e uma série de outros valores e códigos de conduta. Bonfim define o trabalho do design através dessa perspectiva:

O design seria, antes de tudo, instrumento para a materialização e perpetuação de ideologias, de valores predominantes em uma sociedade, ou seja, o designer, conscientemente ou não re-produziria realidades e moldaria indivíduos por intermédio dos objetos que configura. (BONFIM,1997.p.32) 
Pensando nas definições de arte e design, podemos dizer que o design estaria em um caminho de continuidade em relação à ordem das coisas, enquanto as artes plásticas estariam na direção oposta, de desconstrução do status quo, de ruptura com os padrões dados. No lugar onde a arte questiona, o design reafirmaria a realidade. Tal postura estaria relacionada, por exemplo, a uma prática de mercado, que encontra a segurança de um investimento em uma solução já conhecida, e também ao aspecto comunicacional próprio do design, que buscaria formas reconhecíveis para se relacionar de forma mais direta com o usuário.

$\mathrm{O}$ fato de tanto a arte como o design terem, em geral, um resultado visual como preponderante não quer dizer que são a mesma coisa. Segundo Adrian Forty, na introdução de 'Objetos do Desejo', essa confusão estaria na raiz do problema fundamental de definir a área e de uma imagem errônea do design que se propaga em diversos meios:

A concepção e a fabricação de sua obra permitem aos artistas considerável autonomia, o que levou à crença comum de que uma das principais funções da arte é dar livre expressão à criatividade e à imaginação. Seja correta ou não essa visão da arte, o fato é que ela certamente não é verdade para o design. (FORTY, 2007,p.13)

Washington Lessa trabalha a definição da arte segundo o conceito de Deleuze e Guattari, que dizem que dentre as formas de ordenar o caos a arte seria aquela que o abraça e busca sua cristalização, porém sem perder sua característica caótica "A arte quer criar um finito que restitua o infinito" (DELEUZE, GUATTARI, apud LESSA, 2001, p.84), estando assim avessa aos clichês e convenções sociais. E afirma:

Diferentemente desta diretriz, o trabalho do designer se baseia em tipos de produtos ou de funções operativas já caracterizados e em formulações de linguagem já consolidadas. A função deve ser reconhecida e o conteúdo deve ser comunicado. Neste contexto ganha peso a questão da maestria, pois a invenção artística estaria limitada tanto pela predeterminação da necessidade e do programa do trabalho, quanto pela pressão dos agentes do mercado, que, inercialmente, optam por gêneros amarrados e soluções conceituais e formais já testadas. (LESSA, 2001, p.84)

A busca por novas alternativas não é impossível e o designer comprometido com sua prática muitas vezes se aproxima do pensamento e fazer artístico na busca de formas e conceitos mais inovadores sem ignorar, no entanto, sua posição dentro de 
uma cadeia produtiva. Não existe design fora do mercado e da cultura de massa, por mais que seus processos possam em alguns casos se assemelhar aos da arte.

O método é um dos aspectos determinantes na delimitação de uma área como produtora de conhecimentos. Bonfim aponta para a falta de uma metodologia própria do design; sendo uma disciplina essencialmente interdisciplinar, ela se valeria de métodos diversos dependendo de cada projeto. $\mathrm{Na}$ prática o que acaba acontecendo em muitos casos é a formulação dos fundamentos teóricos depois da solução pronta a fim de justificar os resultados obtidos.

Os métodos 'caixa preta' e 'caixa transparente' são descritos como duas grandes classes metodológicas que se alternam no processo de produção, ou criação, em design. No método do tipo 'caixa preta' o processo de criação é obscuro, pressupõe-se que partindo de um determinado problema o designer teria uma capacidade 'inata' de chegar a uma solução a partir dos conhecimentos dados. Por outro lado no método do tipo 'caixa transparente' a relação causal de um problema para uma solução é clara e justificada por método científico, e não haveria, portanto, muito espaço para variação de resultados (BONFIM, 1997, p.33).

Nesse sentido a arte estaria muito mais identificada a um processo 'caixa preta', por mais que se esforce muitas vezes em evidenciar o processo, senão de criação intelectual, pelo menos de fabricação da obra. A intuição e a criatividade são comumente vistas como descoladas de um processo racional, associados à uma expressão individual e espontânea.

A arte como sendo da ordem da criatividade aparece também na discussão que Rita Couto faz sobre o design como corpo de conhecimentos (COUTO, 1997, p.2). A dicotomia que percebemos em diversos discursos entre os métodos racionais e intuitivos colocou o design nesse jogo de "cabo-de-guerra" que o leva ora para o lado científico, ora para o lado artístico de acordo com o interesse em questão.

O design tem uma dimensão criativa inegável e um papel preponderante na construção do imaginário de forma não muito distinta das artes visuais. A imagem do designer como projetista, usando métodos racionais em prol de uma visão maior de resultado, em oposição ao artista como mestre de uma estética e visão particular, tampouco se sustenta como forma de diferenciá-los. O artista como projetista muito menos é uma novidade; desde a Renascença podemos apontar artistas que se valem de mão de obra de ajudantes para levar a cabo seus projetos e nem por isso podemos chamá-los de designers, ainda que o processo se assemelhe. O artista pode projetar, 
esboçar, conceituar e planejar a fabricação de suas obras de forma não muito distante do processo de projetar uma peça de design.

Esse ruído da arte como livre expressão de um autor se dá pelo afastamento da técnica como fundamento das Belas Artes. Paralelo a esse movimento, o nascimento do design como 'artes aplicadas' no século 19 dividiu o campo. As artes visuais gradativamente se voltam para preocupações além da representação em si, dando início a uma nova maneira de pensar o campo, mais relacionada a questões particulares da área.

Os desdobramentos do pensamento em design, por sua vez, o levaram muito além do reducionismo que o termo 'arte aplicada' nos leva a crer, como algo superficial ou ornamental. A educação do gosto, a redução da forma pela função, o apreço pela máquina foram alguns dos ideais que a área levantou com o modernismo, destacando o design como área autônoma, ainda que híbrida. O design se volta ainda para uma preocupação ética e social em relação aos produtos que coloca no mundo, e as ciências sociais entram em cena como a grande aliada para o entendimento da relação que estabelecemos com esses produtos. O usuário se coloca de vez no centro do universo do projeto.

Apesar do senso comum muitas vezes estar estacionado no século 19, a concepção tanto do design como da arte mudaram muito quando analisadas de perto. O campo do design se expandiu para além do produto sensível, e sua forma de pensar o projeto aliada à prática é hoje vista como seu grande valor. A arte contemporânea também não é necessariamente definida pelas pinceladas de um gênio criativo, senão por conceitos transformados em projetos, muitas vezes interativos, muitas vezes não visíveis, e assim em diante.

Arte e design, independente de barreiras conceituais, formulam suas práticas de acordo com objetivos que variam com cada projeto. Aponta-se então a ilustração como essa área concorrente de saberes onde tanto o design, que se definiu por uma forma específica de resolver questões, quanto a arte, com toda sua história, filosofia e repertório, contribuem cada um de seu modo na construção de narrativas. Tais formas de pensar se sobrepõem na criação de representações, tendendo para cada um dos lados de acordo com a proposta e o projeto.

Não seria possível falar de ilustração no contexto proposto de uma coleção de livros infantis sobre Cândido Portinari sem se aprofundar minimamente na discussão sobre arte e design. Fica claro que se a arte e o design constituíram caminhos e 
questões distintas ao longo do tempo, na ilustração elas se encontram em fronteiras mais difusas, mas nem por isso menos interessantes. Veremos que a questão se desenvolve justamente na representação e, finalmente, na interpretação dessas narrativas, tendo o leitor como o ponto de partida para o projeto.

\section{ILUSTRAÇÃO EDITORIAL COMO PROJETO}

Diferente das artes plásticas, a ilustração editorial se define teoricamente pela representação, ou interpretação, de um conteúdo verbal. Independente do tipo de relação que se estabelece, a ilustração está geralmente subordinada à uma narrativa, e não deveria ser analisada separadamente desta, mesmo que essa narrativa seja sugerida e não apareça na forma de texto escrito.

Seria, portanto, mais que uma expressão plástica, a capacidade de simbolizar, trazer para o presente da imagem os sentidos e sentimentos de uma história. É a possibilidade de tornar real e imaginário ao mesmo tempo. A imagem pode até ganhar o terreno artístico e se desprender do texto, mas podemos argumentar que enquanto ilustração ela não é o desenho, ou a imagem em si, mas o uso que se faz desta. É a imagem e seu significado dentro de um contexto narrativo.

A ilustração pertence, no geral, a um universo visual reconhecível, ou senão sua leitura se torna possível a partir da narrativa que acompanha. Ela parte do real, ou ao menos do texto, para ser interpretada, e é o espaço para o leitor se projetar minimamente naquele espaço cênico. Como no caso do design, os clichês não são necessariamente tidos como falta de originalidade, senão como formas de comunicação.

Mesmo assim, a função da ilustração editorial, principalmente quando pensamos no livro ilustrado infantil, não é dar forma acabada aos personagens e à história, e sim, idealmente, criar uma nova maneira de olhar e acrescentar outras camadas de entendimento para uma narrativa. É tornar crível o universo do fantástico, materializar a imaginação sem torná-la real. Assim, se uma imagem respeita o universo cognitivo do seu público não existe estilo ou ilustração mais apropriada que outra.

O par realidade e imaginação está na própria definição de representação. Esta, segundo a semiótica, estaria entre a apresentação e a imaginação (SANTAELLA, 2010, p.6). Pois ao mesmo tempo em que faz referência a um objeto, ou realidade fora 
dela, também cria algo de novo. As representações são sempre aproximações condicionadas pelo nosso olhar, e o olhar e o interpretar dependem da experiência pessoal, social e cultural.

Essa sobreposição do reconhecível e do imaginado nos remete ainda às distinções analisadas anteriormente sobre arte e design. Como definiu Lessa:

Deste modo, são necessariamente diferentes os procedimentos visuais e conceituais do Design e da arte. Esta, através de um livre exercício formal/conceitual, tende a abrir o horizonte das possibilidades de linguagem, enquanto o Design tende a trabalhar sobre características formais e programas funcionais já dados. (LESSA, 2001, p.85)

A ilustração, no caso, funciona em ambas as dimensões, do real e do imaginário, trabalhando as possibilidades de linguagem através de características formais existentes e reconhecíveis. Dessa forma podemos argumentar que o trabalho do ilustrador se situa nessa fronteira entre arte e design. E quando pensamos em livros ilustrados estamos presumindo um objeto sequencial que geralmente demanda um projeto de design. As ilustrações seguem uma mesma lógica ao longo do livro e estão integrando um projeto gráfico que supõe um sentido como todo, o que é uma visão característica de projeto de design, dando coerência e identidade.

Disso surge outra questão, pois a ilustração e o projeto gráfico também não são necessariamente coisas distintas, apesar de em muitos casos serem separados claramente; sendo cada um realizado por um profissional, já encontramos muitos livros ilustrados onde não é possível fazer tal diferenciação. Nesse sentido a interdisciplinariedade no trabalho conjunto desses diferentes atores na produção do objeto- livro só tem a acrescentar à experiência de leitura (LACERDA, 2013, p. 60).

A ilustração pode se integrar de tal forma ao projeto de design que a narrativa, ilustração e o próprio objeto livro se tornam uma coisa só. É o caso por exemplo da famosa série de Suzy Lee, onde o formato, a ilustração e os elementos constitutivos do livro, como a costura e as páginas conversam entre si na construção da narrativa. 


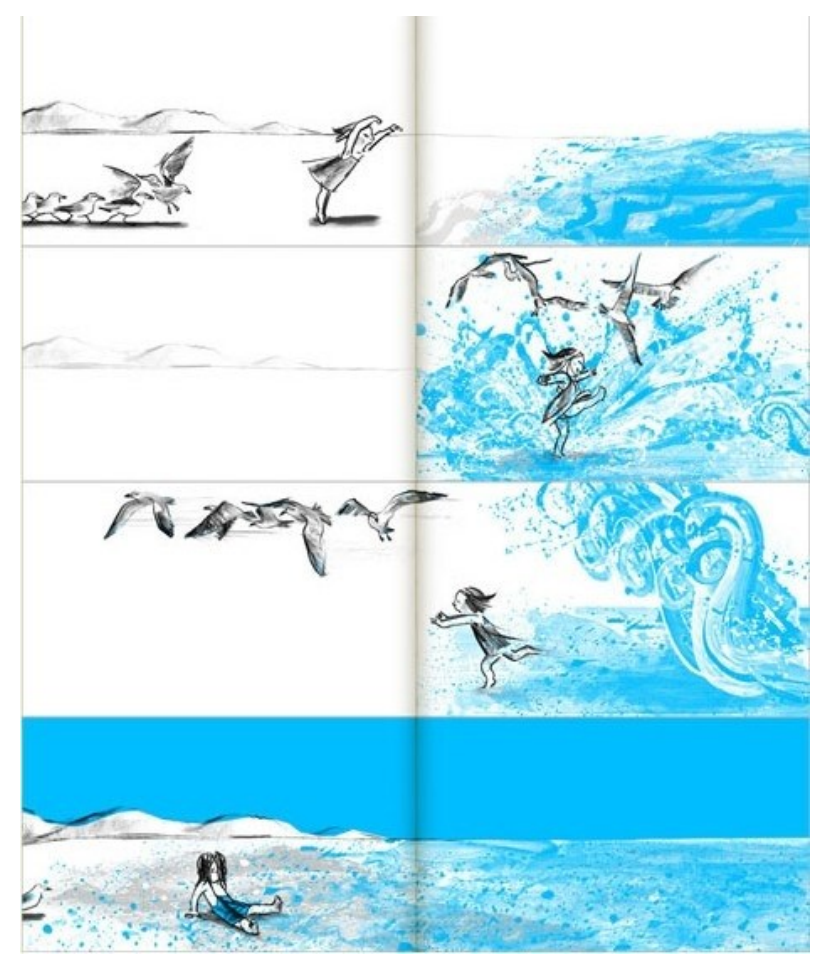

[Fig 6. “A Onda”, Suzy Lee]

As divisões da página dupla, a forma como abrimos o livro, etc. são aproveitadas pela autora para contar sua história, se tornando elementos indispensáveis no desenvolvimento da narrativa. É inegável aqui a dimensão projetual da obra, abrangendo forma, conteúdo e mesmo a existência de um leitor presumido e sua interação com aquele objeto. A dimensão visual, plástica da ilustração, por outro lado, não foge de um caráter 'artístico' e subjetivo, explorando livremente as possibilidades da linguagem, para usar a definição de Lessa, com traços e aquarelas caraterísticos da autora.

Outro exemplo é o livro infantil "Press Here" que sem se valer de nenhuma tecnologia cria uma dimensão interativa com o leitor. As imagens das bolinhas não deixam de ser ilustrações, uma vez que constituem a própria narrativa proposta, mas seu aspecto subjetivo e interpretativo é limitado por uma linguagem mais objetiva que serve ao projeto do livro. 

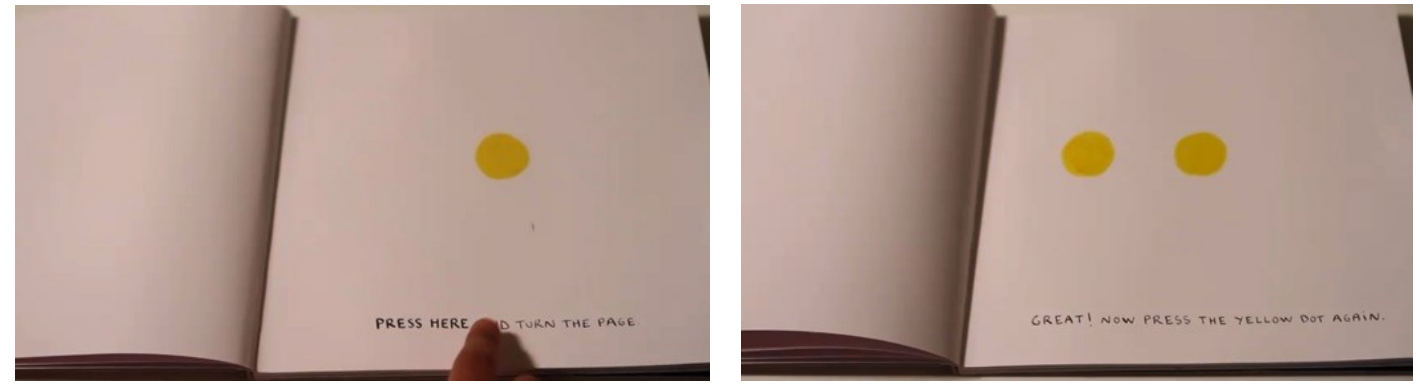

[Fig 7. "Press Here", Herve Tullet]

De qualquer forma, não é por ser sintético e se valer de elementos icônicos que uma ilustração perde sua profundidade subjetiva. Um exemplo definitivo disso é a obra de Ziraldo, Flicts, que através de massas chapadas de cor e elementos simbólicos muito objetivos narra uma história de rejeição e busca de identidade que permite diferentes camadas de leitura.

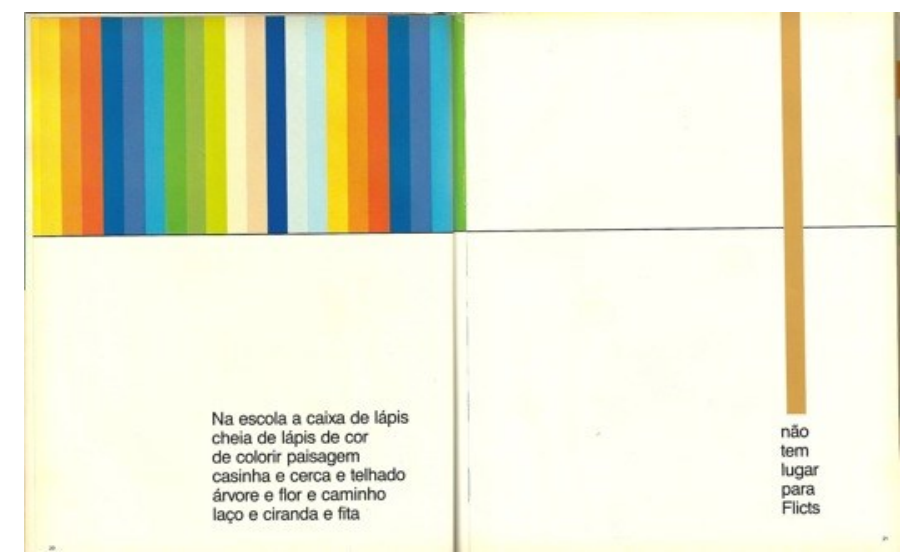

[Fig 8. "Flicts", Ziraldo]

Em "Livro ilustrado: palavras e imagens", de Maria Nikolaje e Carole Scott, as duas autoras fazem uma análise bastante completa da relação entre os dois tipos de linguagem no objeto em questão. Apesar da imagem poder estar associada ao signo convencional, principalmente quando se trata de alguns pictogramas, ou sinais de trânsito, por exemplo, ela está relacionada principalmente ao signo icônico, ou seja, que faz referência ao real, enquanto o texto seria um código convencional, que não traz em si a forma de decifrá-lo. Assim, apesar de tanto o texto como a ilustração serem imagem, sua diferença enquanto signo convencional e icônico, respectivamente, é que vai gerar a tensão mais interessante na criação de significados. 
Enquanto o texto comunica contando, a imagem comunica mostrando. A imagem teria 'vantagem' sobre o texto na descrição de uma cena; a ambientação, a caracterização e a noção espacial são compreendidas instantaneamente com uma imagem. O que o texto omite visualmente pode ser trabalhado livremente na ilustração, agregando outros elementos e construindo sentidos diversos.

Por outro lado a ilustração não suportaria a questão temporal e psicológica, geralmente ela representa um momento congelado. Em um filme existem alguns recursos, como a voz em off, ou o flashback, para contornar essa questão, mas continua sendo aquele instante na tela quando pensamos em imagem. Não temos na ilustração o aprofundamento do momento que o texto permite nem a relação de causalidade e temporalidade essenciais para a narrativa. Ainda que a imagem possa passar alguns aspectos psicológicos, o texto o faz com muito mais precisão. "As imagens possibilitam uma diversidade de caracterizações externas, enquanto as palavras podem ser usadas tanto para descrição externa como para 'representação' interna." (SCOTT e NIKOLAJEVA, 2011, p.113)

É nessa interação que surgem novas propostas e soluções. Texto e imagem nunca vão coincidir, como algumas análises as vezes podem sugerir. De qualquer forma essa separação texto e imagem é de certo modo artificial pois ambas dimensões da narrativa caminham paralelamente.

Para o filósofo e fotógrafo Evgen Bavcar, que perdeu a visão ainda muito jovem, quem faz a mediação entre a imagem verbal e a visual é o artista. Mas são elas inseparáveis. Diz Bavcar que “... nesta perspectiva, o artista é, sobretudo, o mediador entre as trevas do verbo, do fundo de sua cegueira, e a evidência concreta da imagem, tal como realizada na arte através de um ou outro suporte material." (BAVCAR, 1994, p. 461)

A relação da imagem com o verbo, ou a palavra, torna-se, assim, bastante clara: uma não existe sem a outra. E como afirma Bavcar, a imagem é condição para o texto verbal e vice-versa. O texto narrativo, portanto, ainda que não tenha figuras, também evoca imagens mentais. Estas, por sua vez, também são dotadas de tempo e sentido caracteristicamente narrativos. Para Manguel, “...a imagem dá origem a uma história, que, por sua vez, dá origem a uma imagem" (MANGUEL, 2001, p. 24). O limite formal que normalmente se atribui à narrativa verbal como própria de uma descrição no eixo temporal enquanto que a narrativa imagética se desdobra no eixo espacial é muito relativo. As duas dimensões narrativas estão em constante diálogo. 
A representação em imagens de uma história revela um olhar sobre ela ao mesmo tempo em que a altera para o leitor. Tão poderosa é a imagem que Flaubert recusava que seus livros fossem acompanhados de ilustração "porque a descrição literária mais bela é devorada pelo mais reles desenho.” (MANGUEL, 2001, p. 20). Mas se uma ilustração pode limitar as imagens que criamos durante a leitura, ao mesmo tempo pode multiplicar os sentidos do texto, sentidos não necessariamente descritos verbalmente, além de criar uma dinâmica de leitura diferente, que interage com o leitor em outro nível.

Peter Hunt, especialista em literatura infantil, fala sobre as possibilidades dessa interação:

Os livros ilustrados podem explorar essa relação complexa; as palavras podem aumentar, contradizer, expandir, ecoar ou interpretar as imagens - e vice-versa. Os livros-ilustrados podem cruzar o limite entre os mundos verbal e pré-verbal. (HUNT, 2010, p. 234)

A interação texto e imagem é classificada de diversas formas pelos teóricos da comunicação. Sophie Linden atenta que muitos desses estudos foram feitos tendo em vista as mensagens publicitárias e que o livro, por ser sequencial, tem especificidades próprias. De qualquer forma, podemos pensar que de modo geral o texto pode estabelecer três relações com a imagem: de "redundância", "complementariedade" e “contradição" (LINDEN, 2011, p. 120).

Uma redundância completa, na qual as mensagens verbal e visual coincidem, seria obviamente impossível. A redundância é definida, quando as mensagens não dependem, uma da outra, para produzir sentido, uma não acrescenta à outra. Assim, o que está no texto é mostrado na imagem, e nada além. Ao contrário, se existe uma relação de complementariedade, a imagem e o texto constroem o sentido em conjunto, combinando as qualidades de cada código para chegar a um discurso único através dessa articulação. Já a relação de contradição ou disjunção, menos frequente, mas não menos interessante, seria quando a imagem não coincide com o texto em algum aspecto, ou forma uma narrativa paralela, o leitor é convidado a construir um sentido a partir das duas mensagens.

Essa classificação funciona como um bom começo para pensarmos as muitas variedades possíveis da relação da ilustração com o texto. A imagem pode imprimir ritmo, ampliar a narrativa, mostrar mais do que o que está escrito, criar histórias paralelas e aumentar o enredo. Ela pode ainda sugerir novas interpretações, preencher 
lacunas no texto, criar metáforas, enfim, uma infinidade de formas de interação que tornam a narrativa híbrida.

No âmbito das artes visuais a ilustração é geralmente vista como algo de menor valor quando comparada à pintura ou à escultura. E esse movimento de valorização da imagem como parte integrante da narrativa nos livros ilustrados é relativamente recente. Até não muito tempo atrás a ilustração era vista como ornamento ou adorno, e o valor estaria mesmo no texto verbal. E mesmo o processo de seleção das editoras partiam dos originais em texto para posteriormente dar forma à história, dificilmente veríamos um pensamento em conjunto.

Alan Powers introduz a história do livro ilustrado apontando a mesma questão do verbal versus visual discutida aqui:

\begin{abstract}
O descaso pelas capas de livro resulta de uma disputa entre a palavra e a imagem nos processos de edição e de leitura. A tendência de as crianças lerem as ilustrações, e não o texto, implicou a visão de que capas atraentes demais degradam conteúdos importantes - paradigma que talvez ainda seja corrente no caso das publicações acadêmicas. (POWERS, p.5)
\end{abstract}

Partindo dessa reflexão sobre o papel da imagem e através dos exemplos mencionados anteriormente podemos ver que a ilustração e seu poder de comunicação estão muito além de um saber meramente técnico, ou do domínio de uma forma de representação. As possibilidades de comunicação são inesgotáveis quando pensadas dentro da relação da imagem com a narrativa e sua relação com o leitor.

\title{
UM PROJETO INFANTIL PARA PORTINARI
}

O processo de criação da coleção Portinari partiu do pressuposto que a condução da narrativa seria feita através das obras do pintor. Assim, antes de pensar no projeto gráfico, o texto já estava sendo elaborado com um encadeamento de imagens. A história é contada com frases curtas e ritmadas e em sua maioria chamam atenção para um elemento da obra.

As pinturas e desenhos de Portinari estavam funcionando desde o início do projeto como ilustrações para a narrativa, e como num processo inverso do que acontece na maioria dos casos, o texto estava sendo criado a partir das imagens. Poderíamos ter feito apenas uma diagramação sem muita perda de conteúdo, relacionando as obras com uma narrativa. 
A narrativa que cada pintura possuía separadamente se diluiu na sequência do livro para se tornar uma coisa só. Ou seja, a relação entre as obras e a narrativa não obedeceu nenhuma regra, seja cronológica seja de temática. Para tomar o primeiro livro como exemplo, pinturas que não se relacionavam diretamente com a infância do pintor passavam a fazer parte daquele universo. Em "Os Meninos", a narrativa tem o único propósito de criar uma relação da infância do pintor com a infância retratada por ele.

Ao pensar o projeto gráfico, em primeiro lugar, as obras deveriam estar claramente destacadas, uma vez que foram elas que conduziram a narrativa, e não o oposto. Em segundo lugar, um elemento gráfico que fazia essa mediação entre obra e a narrativa para unificar graficamente o que tinha sido unido primeiramente pelo texto. Assim, as pinturas antes vistas como obras separadas ganhariam um universo cênico onde se encontrariam para contar aquela história.

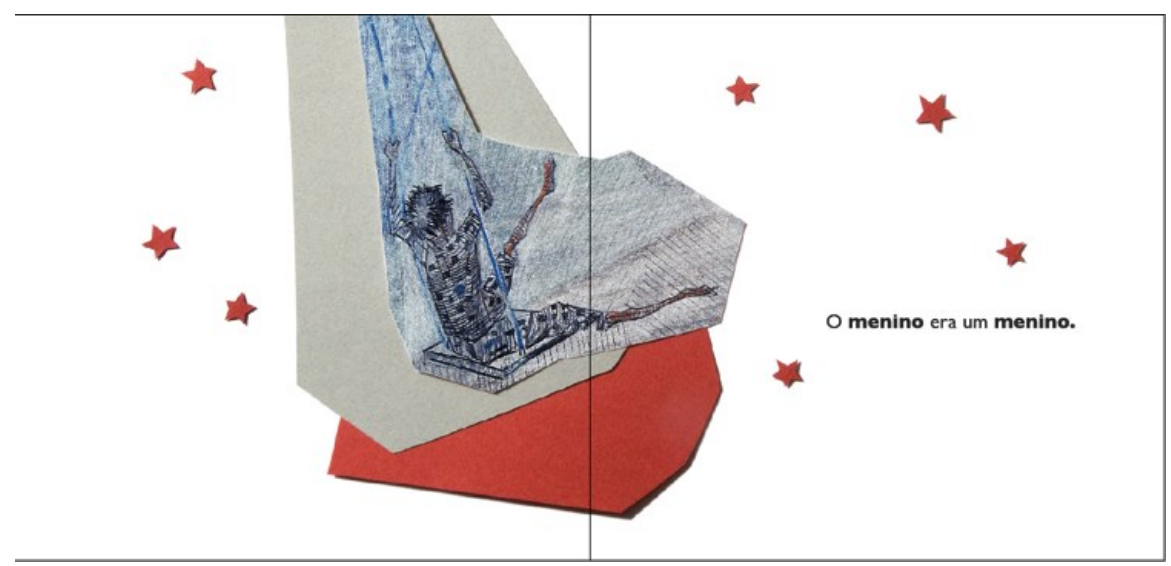

[Fig.9, "Os Meninos”, Coleção Portinari para crianças]

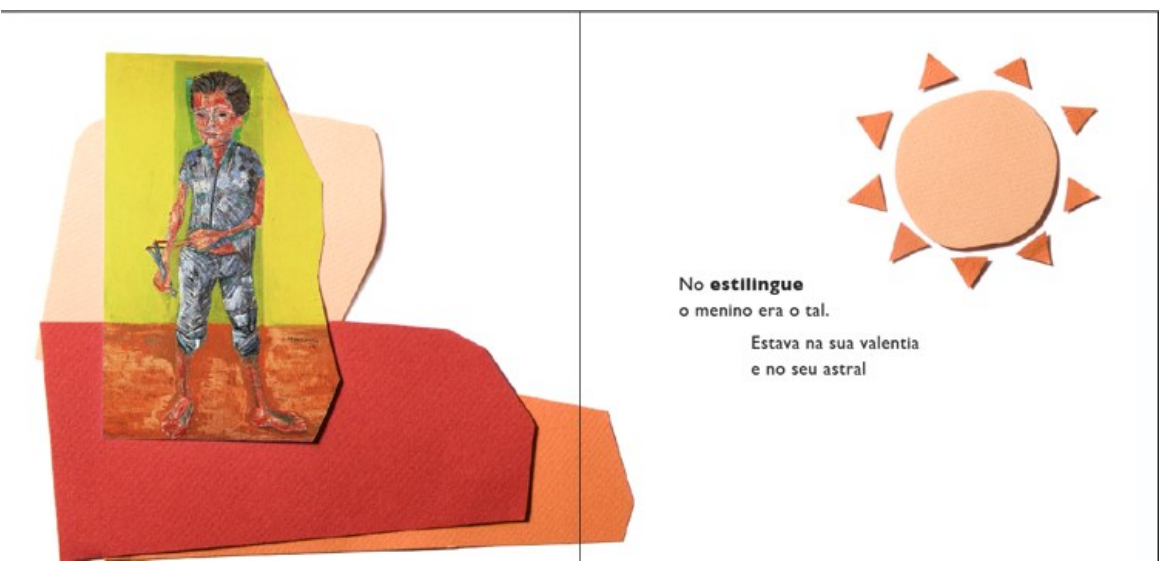

[Fig.10, “Os Meninos", Coleção Portinari para crianças] 


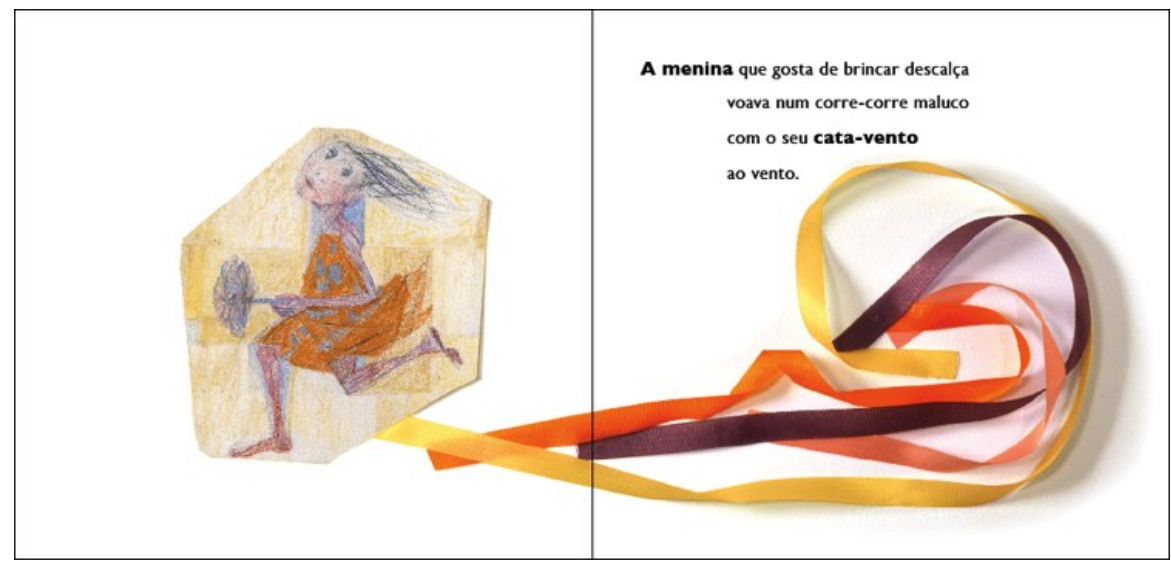

[Fig.11, “As Meninas”, Coleção Portinari para crianças]

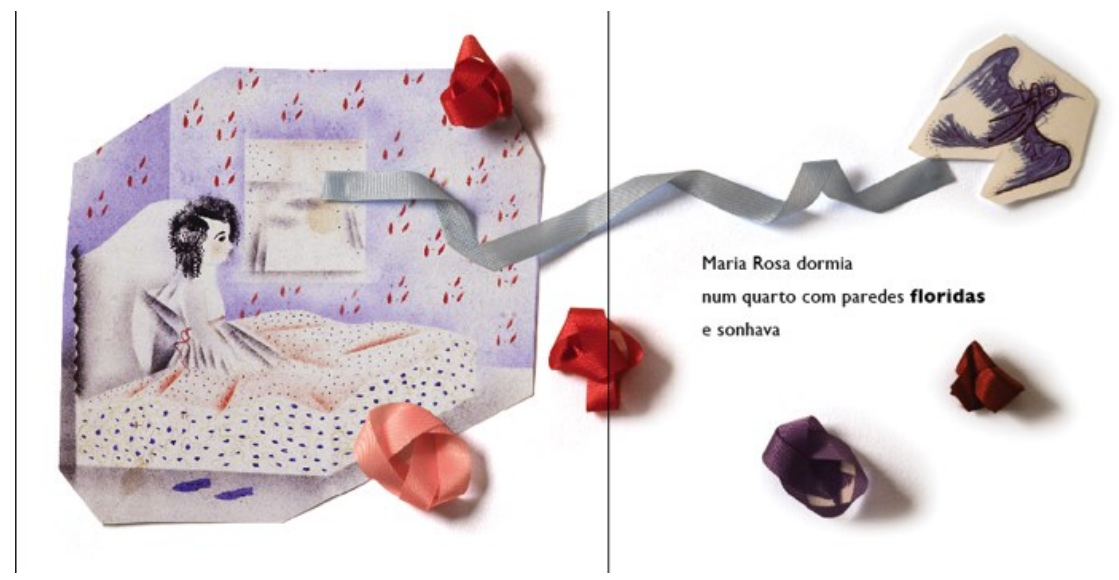

[Fig.12, “As Meninas”, Coleção Portinari para crianças]

Como o texto fazia referência direta às cenas pintadas e não aos quadros, não seria possível usar o artificio de "Linéia" ou tantos outros de colocar a pintura representada como pintura, ou seja, com uma moldura e pendurada na parede. Nem acredito, pessoalmente, que seria a introdução mais interessante para a arte, no caso das crianças menores, apresentá-la como algo separado da vida e reverenciado como um valor. Pensando por esse lado elas poderão ver placas suficientes nos museus que dizem "não encoste nas obras".

A solução encontrada foi usar as imagens das obras de Portinari integradas em uma colagem. Esse aspecto de colagem deveria ser claramente percebido, de maneira que a obra não se confundisse com a intervenção e se destacasse claramente dela. A materialidade da composição não deveria deixar dúvida de o que é pintura e desenho de Portinari e o que é intervenção. As colagens dessa forma, apesar de representarem 
cenários e objetos, enfatizam muito mais as cores e materiais que propriamente a forma.

Como cor e texturas são elementos muito trabalhados na faixa etária pré alfabetização, além de serem matéria prima da pintura, achamos que seria interessante trazer diferentes materiais para o projeto, o que acabou se desdobrando para os demais livros da série.

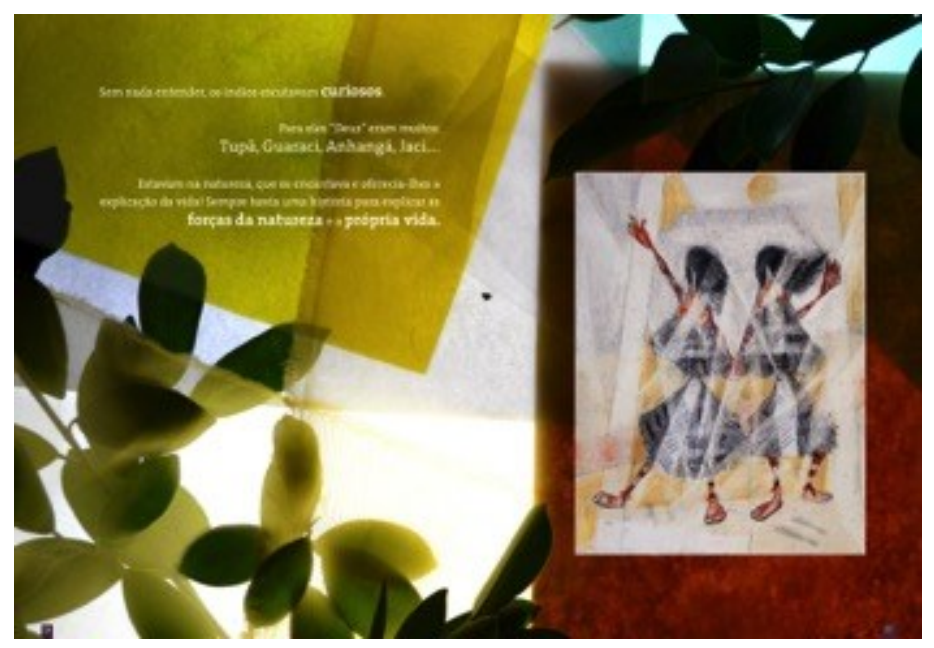

[Fig.13, "História do Brasil em traços e cores", Coleção Portinari para crianças]

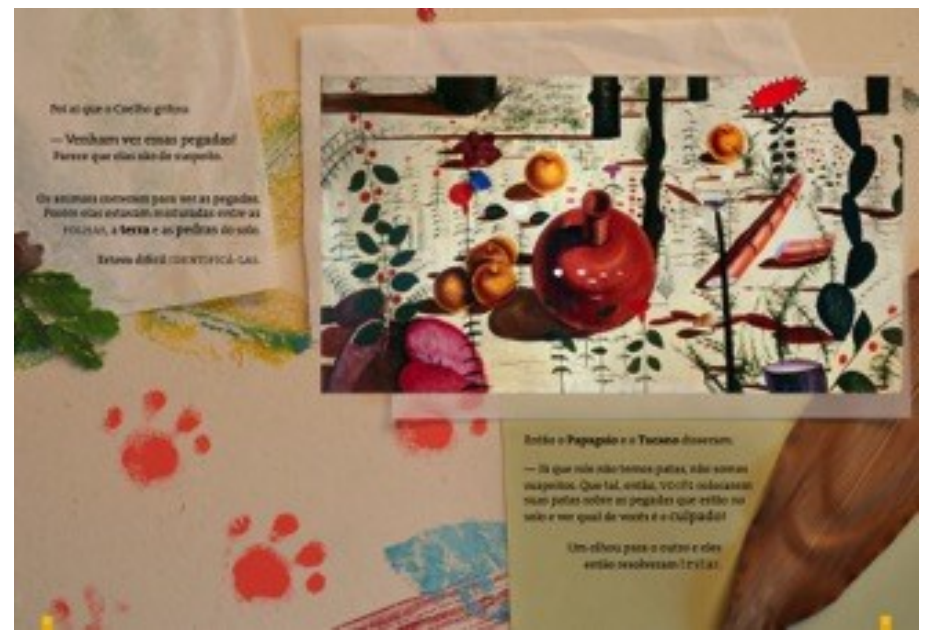

[Fig.14, "Festa na Floresta Brasileira", Coleção Portinari para crianças]

A intenção com esses elementos seria criar uma superfície mais familiar e clara de contato entre a criança e a pintura. As cores chapadas e a textura são objetivas e criam uma relação com os temas representados por Portinari, idealmente sem criar confusão entre um e outro. Independente de qualificar se essas intervenções 
como ilustração ou como projeto gráfico, o fato é que são uma decisão de projeto, pensada justamente com o leitor em mente.

A ilustração, no caso em questão, mediaria não somente o entendimento do texto, como a própria interpretação que se pode ter das obras do pintor, independente do texto verbal. Certamente o olhar antecede o verbo e a criança não faz a separação entre forma e conteúdo que talvez, no final, não exista mesmo. De qualquer forma, a criança é capaz de formar uma relação com o livro independente do que ele contém. Se é o ilustrador que cria a imagem, ela só se concretiza e existe de fato através do olhar desse pequeno leitor. E isso ocorre de forma afetiva passando por tudo que ele já viu e pelo o que ele espera ver ali.

A consideração de um objeto, qualquer que seja, supõe inicialmente a existência de um sujeito. Não há sentido um objeto sem sujeito, pois o objeto, entendido como 'coisa', 'fato', 'representação', 'conceito', 'pensamento' etc., só existe dentro dos limites de nossas experiências, de nosso conhecimento e de nossas linguagens. Assim, as características de um objeto são, na verdade, as interpretações subjetivas que dele fazemos. (BONFIM, 1997.p.37)

A ilustração no livro infantil foi muitas vezes tratada como uma "muleta", uma forma de transmitir ideias e significados até a criança ser capaz de ler o texto escrito com propriedade. Hoje, no entanto, podemos inclusive pensar em livros ilustrados para adultos. Sophie Van der Linden introduz seu estudo tentando quebrar essa visão:

...inicialmente destinado aos mais jovens, a priori menos experientes em matéria de leitura, ele se consolida como uma forma de expressão por seu todo, e não exige menos competência estabelecida e diversificada de leitura. ( LINDEN, 2001, p.7)

Como forma de expressão, portanto, o livro ilustrado pressupõe uma liberdade formal. As soluções de projeto aqui não deixaram de ser uma forma de expressão e um olhar particular de como seria uma visão infantil da obra de Portinari.

O papel comunicador do design, a forma de pensar o projeto e a criança como principal interlocutor permearam o processo de criação. Além disso, a função da arte e do design como representações culturais, cada qual com sua particularidade, tornam o projeto, de certa forma, um objeto de diálogo, não abrindo mão de um reconhecimento da arte como transformador da sociedade, nem do design como esse possível interlocutor, e que, como qualquer mediador, não passa sem deixar sua marca. 


\section{CONCLUSÃO}

Esperamos, dessa forma, ter criado uma relação mais afetiva que didática com a obra do pintor e possibilitado uma aproximação menos reverencial e mais lúdica com a arte de forma geral.

Determinar se ilustração faz parte do campo da arte ou do design não é a maior discussão que poderíamos gerar, senão problematizar o que cada visão pode oferecer para a criação de narrativas visuais e construção de significado em livros ilustrados.

Repensar esses pontos de contato, além de levantar algumas reflexões sobre o papel da imagem e sua relação com a narrativa e com a construção de significados, certamente trouxe um novo olhar para a prática de projeto.

O processo de criação da coleção dos livros em parceria com o Projeto Portinari segue uma série de problemas típicos do campo do design, como questões de produção e aceitação em escolas como forma de facilitar a distribuição, ao mesmo tempo em que são objetos de expressão e de comunicação de um conteúdo. A arte de Portinari não deixa de ser valorizada com a intervenção da ilustração, muito pelo contrário, ela ganha uma nova possibilidade de diálogo e interação com os pequenos leitores, ou pelo menos, assim esperamos.

\section{REFERÊNCIAS}

BOMFIM, Gustavo Amarante. Fundamentos de uma teoria transdisciplinar do Design: morfologia dos objetos de uso e sistemas de comunicação. Estudos em Design, v. v, n.2, p. 27-41, dez. 1997.

COUTO, Rita. Design como corpo de conhecimentos. Em: Movimentos interdisciplinares de designers brasileiros em busca de educação avançada. Tese de Doutorado. Rio de Janeiro: PUC, 2007

FORTY, Adrian. Objetos de desejo - Design e sociedade desde 1750. São Paulo: Cosac Naify. 2007

HUNT, Peter. Crítica, teoria e literatura infantil. São Paulo: Cosac Naify, 2010

LACERDA, Maíra. Design na Leitura: uma possibilidade de mediação entre o jovem e a leitura literária. Dissertação de 2013/PUC-Rio 
LESSA, Washington Dias. Prática de Design e Conhecimento. Designe, Rio de Janeiro, ano III, $n^{\circ} 3$, p. 80-86, outubro 2001

LINDEN, Sophie Van der. Para ler o livro ilustrado. São Paulo: Cosac Naify, 2011

MANGUEL, Alberto. Lendo Imagens. São Paulo: Companhia das letras, 2001

OLIVEIRA, Rui de. Pelos Jardins Boboli. Reflexões sobre a arte de ilustrar livros para crianças e jovens. Rio de Janeiro: Nova Fronteira, 2008.

POWERS, Alan. Era uma vez uma capa. História ilustrada da literatura infantil. São Paulo: Cosac Naify, 2008

SANTAELLA, Lucia e NOTH, Winfried. Imagem: Cognição, semiótica, mídia. São Paulo: Iluminuras, 2008

SCOTT e NIKOLAJEVA, Carole e Maria. Livro ilustrado: palavras e imagens. São Paulo: Cosac Naify, 2011.

SCOTT e NIKOLAJEVA, Carole e Maria. Livro ilustrado: palavras e imagens. São Paulo: Cosac Naify, 2011.

\section{A AUTORA}

Julia Lima L. Carvalho é designer formada em Comunicação Visual pela PUC-Rio, com especialização em Comunicação e Imagem pela mesma instituição, defendeu em 2014 o mestrado no departamento de Artes e Design, com dissertação sobre ilustração e representação da personagem diferente em livros infantis. Atuante no mercado como designer e ilustradora desde 2008, atualmente compõe também o Grupo de Estudos em Literatura Infantil e Juvenil no Instituto Interdisciplinar de Leitura.

E-mail: julia.limac@gmail.com 